\title{
Patients Prefer Pictures to Numbers to Express Cardiovascular Benefit From Treatment
}

\author{
Felicity Goodyear-Smith, MBCbB, \\ MGP, FRNZCGP ${ }^{1}$ \\ Bruce Arroll, MBCbB, PbD, \\ FRNZCGP ${ }^{1}$ \\ Lydia Chan, BSc ${ }^{1}$ \\ Rod Jackson, MBCbB, PbD, \\ FAFPHM ${ }^{2}$
}

Sue Wells, MBCbB, Dip Obs, MPH, FRNZCGP, FAFPHM ${ }^{2}$

Timotby Kenealy, $M B C b B, P b D$, FRNZCGP ${ }^{3}$

'Department of General Practice and Primary Health Care, The University of Auckland, New Zealand

${ }^{2}$ Section of Epidemiology \& Biostatistics, The University of Auckland, New Zealand

${ }^{3}$ Faculty of Medical and Health Science, The University of Auckland, New Zealand

Conflicts of interest: none reported

\section{CORRESPONDING AUTHOR}

Felicity Goodyear-Smith, MBChB Department of General Practice and Primary Health Care

School of Population Health, Faculty of Medical and Health Science

University of Auckland

PB 92019 Auckland, New Zealand

f.goodyear-smith@auckland.ac.nz

\begin{abstract}
PURPOSE This study aimed to determine which methods of expressing a preventive medication's benefit encourage patients with known cardiovascular disease to decide to take the medication and which methods patients prefer.

METHODS We identified patients in Auckland, New Zealand, family practices located in areas of differing socioeconomic status who had preexisting heart disease (myocardial infarction, angina, or both) and were taking statins. The patients were interviewed about their preference for methods of expressing the benefit of a hypothetical medication. Benefits were expressed numerically (relative risk, absolute risk, number needed to treat, odds ratio, natural frequency) and graphically. Statistical testing was adjusted for practice.
\end{abstract}

RESULTS We interviewed 100 eligible patients, representing a 53\% response rate. No matter how the risk was expressed, the majority of patients indicated they would be encouraged to take the medication. Two-thirds (68) of the patients preferred 1 method of expressing benefit over others. Of this group, 57\% preferred the information presented graphically. This value was significantly greater $(P<.001)$ than the $19 \%$ who chose the next most preferred option, relative risk. Few patients preferred absolute risk $(13 \%)$ or natural frequencies $(9 \%)$. Only a single patient (1\%) preferred the odds ratio. None preferred number needed to treat. Ninety percent of patients responding to a question about framing preferred positive framing (description of the benefit of treatment) over negative framing (description of the harm of not being treated).

CONCLUSIONS Although number needed to treat is a useful tool for communicating risk and benefit to clinicians, this format was the least likely to encourage patients to take medication. As graphical representation of benefit was the method patients preferred most, consideration should be given to developing visual aids to support shared clinical decision making.

Ann Fam Med 2008;6:213-217. DOI: 10.1370/afm.795.

\section{INTRODUCTION}

We are drowning in information while starving for wisdom. -E.O. Wilson

0 hared decision making is the centerpiece of the current model of patient-centered care. To realize this goal, patients need to be given, to understand, and to interpret information on their own personal risk ${ }^{1}$ and on the benefits and harms of treatment. Risks and benefits can be expressed in numerous ways, such as odds ratios, number needed to treat (NNT), absolute or relative risk, and natural frequency statements; can be presented as either percentages or proportions; can be positively or negatively framed; and can be displayed in numeric or pictorial formats. 
The way information is presented influences patients' decisions. ${ }^{2}$ Although some studies have examined the effects of manipulating risk and benefit information in clinical settings, given the range of ways the data can be presented and the range of relevant clinical settings, a literature review has demonstrated a relative paucity of evidence in this field. ${ }^{3}$ One study has indicated that patients are more likely to consider taking medication to prevent a heart attack if information on benefit is expressed in terms of the relative risk reduction compared with other methods of risk communication. ${ }^{4}$ A qualitative study of patients with familial hypercholesterolemia found that perceived risk may shift over time in response to social contexts and may be influenced by factors such as cardiac events or deaths in the family, illness experiences, or becoming a parent. ${ }^{5}$ Another qualitative study found that patients participating in focus groups did not think that knowing their risk numbers would necessarily motivate them to change their behavior. ${ }^{6}$

Physicians are also influenced by the way information is presented. One study found that physicians were more likely to prescribe a drug that reduces cardiac events if the trial results were expressed in terms of relative risk rather than absolute risk reduction, percentages of disease-free survival, or $\mathrm{NNT}^{7}$; however, presenting only relative risk information is misleading and potentially coercive. ${ }^{8}$ There may be tension, furthermore, between what health care professionals or payers see as best for the population and what individuals see as best for themselves. Although informing patients of their individual risk may increase their participation in screening programs, evidence is lacking regarding how to improve communication of risk to patients ${ }^{9}$ or patients' informed decision making. ${ }^{10}$

In risk communication, it is therefore necessary to establish not only the format of expression most likely to influence patients' behavior, but also the format they prefer in making informed decisions on their own management, either to adopt an intervention or to avoid unnecessary interventions.

The aim of this study was to determine which methods of expressing benefit would encourage patients with known cardiovascular disease to decide to take preventive medication, and which methods they prefer to help them understand the information.

\section{METHODS}

Our study sample was drawn from patients attending 4 family practices in Auckland, New Zealand, located in 1 low-income, 1 middle-income, and 2 high-income areas. We identified potential participants by searching the practices' electronic medical records according to disease classification and drug prescriptions. Patients were eligible if they had heart disease (myocardial infarction, angina, or both) and were taking a statin. The latter requirement ensured that patients had experience with decision making regarding medications and with taking medication, and it provided a backdrop against which we could propose to them a hypothetical new medication.

To recruit patients, practices mailed the identified patients a participant information sheet, a copy of the study questionnaire, a consent form, and a postagepaid return envelope for the consent form. Patients who had not responded after 10 days were contacted by telephone and invited to participate.

Patients were not eligible to participate if they had any of the following exclusion criteria: (1) prior stroke, because we believed such patients would be more likely to take medication to prevent another event than patients who had only cardiovascular disease $_{i}(2)$ inability to communicate in English; or (3) failure to be contacted after 3 calls made at different times of the day and week.

One of the researchers (L.C.) collected data by telephone interviews, which lasted about 20 minutes. During the interviews, patients were asked questions from the questionnaire that had already been mailed to them, including demographic data (sex, age, ethnicity, formal education), their perceived risk of heart attack over the next 5 years, and their willingness to take a protective heart medication continuously for the rest of their lives, plus 2 additional questions to assess basic numeracy. This telephone approach was more efficient than requiring face-to-face meeting of the researcher with the participant.

The study questionnaire was developed using information from the literature with input from the researchers, and was modified after piloting in 1 clinic. The questionnaire informed patients of a hypothetical new medication that had few adverse effects and would be given to people who have had angina or a heart attack to prevent a future heart attack. For the sake of the study, the risk of a heart attack over the next 5 years was assumed to be $23 \%$ without the medication and $16 \%$ with the medication. These risk estimates were derived from a randomized trial evaluating the effect of cholesterol lowering with simvastatin on mortality and morbidity in patients with a history of myocardial infarction or angina. ${ }^{11}$

Patients were presented with this same medication benefit in 8 different ways (Table 1), consisting of 7 numerical formats (relative risk, absolute risk with positive framing, absolute risk with negative framing, NNT, odds ratio, detailed natural frequencies, and simplified natural frequencies) and 1 graphical format 
Table 1. Patients' Responses to 8 Methods of Expressing Benefit From a Hypothetical New Medication That Would Reduce the Risk of a Heart Attack $(\mathrm{N}=100)$

\begin{tabular}{|c|c|c|c|}
\hline \multirow[b]{2}{*}{ Question (Method) } & \multicolumn{3}{|c|}{ Encouraged to Take Medication Daily, No. } \\
\hline & Yes & No & Undecided \\
\hline $\begin{array}{l}\text { By taking this new medication for } 5 \text { years, you will be } 32 \% \text { less likely to have } \\
\text { a heart attack [relative risk] }\end{array}$ & 85 & 12 & 3 \\
\hline $\begin{array}{l}\text { By taking this new medication for } 5 \text { years, the chances of you having a heart } \\
\text { attack will reduce from } 23 \% \text { to } 16 \% \text { [absolute risk, negative framing] }\end{array}$ & 89 & 11 & 0 \\
\hline $\begin{array}{l}\text { Fourteen people will need to take this new medication for } 5 \text { years for } 1 \text { person } \\
\text { to be prevented from having a heart attack [number needed to treat] }\end{array}$ & 67 & 26 & 7 \\
\hline $\begin{array}{l}\text { The odds of you having a heart attack are } 3 \text { to } 1 \text { without medication and } 5 \text { to } \\
1 \text { if you take the medication for } 5 \text { years [odds ratio] }\end{array}$ & 83 & 15 & 2 \\
\hline $\begin{array}{l}\text { There are } 100 \text { people who have had angina or a heart attack. If they do not } \\
\text { take this new medication, then } 23 \text { will have a future heart attack and } 77 \\
\text { will not. If they all take this new medication for } 5 \text { years, then } 16 \text { people } \\
\text { will have a future heart attack and } 7 \text { will be prevented from having a future } \\
\text { heart attack [natural frequencies, detailed] }\end{array}$ & 75 & 22 & 3 \\
\hline $\begin{array}{l}\text { By taking this medication for } 5 \text { years, the chances of you not having a heart } \\
\text { attack will increase from } 77 \% \text { to } 84 \% \text { [absolute risk, positive framing] }\end{array}$ & 80 & 17 & 3 \\
\hline $\begin{array}{l}\text { Your risk of a heart attack is } 23 \text { in 100. If you take this new medication for } 5 \\
\text { years, it will be } 16 \text { in } 100 \text { [natural frequencies, simplified] }\end{array}$ & 86 & 13 & 1 \\
\hline $\begin{array}{l}\text { These } 2 \text { pictures show in a graph form the risk for } 100 \text { people of having a } \\
\text { heart attack. The first graph shows the risk over } 5 \text { years if the } 100 \text { people } \\
\text { did not take the new medication. The second graph shows what will hap- } \\
\text { pen if all } 100 \text { people take this new medication for } 5 \text { years to prevent heart } \\
\text { attacks [graph] }\end{array}$ & 86 & 12 & 2 \\
\hline
\end{tabular}

\section{Figure 1. Graphic expression of the risk of heart attack for 100 people over 5 years without and with new medication.}

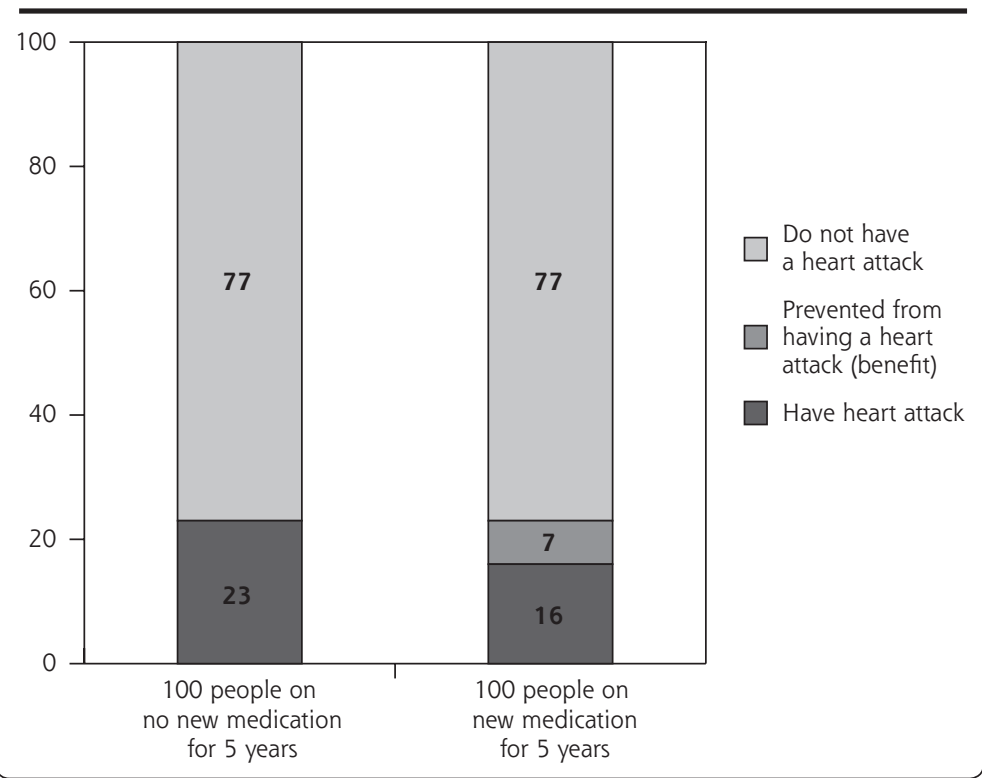

(Microsoft Corp, Redmond, Washington). Statistical tests were undertaken in Stata 9.0 (Stata Corp, College Station, Texas) using the $\chi^{2}$ test, analysis of variance (ANOVA), and logistic regression analysis. The study was approved by the Auckland Ethics Committee.

\section{RESULTS}

We identified 272 patients as potential participants, of whom 84 were ineligible. Of the 188 eligible, invited patients, 100 participated (53\% response rate) 60 were male and 40 were female. Seventyseven were of New Zealand European ethnicity, 16 were of Maori ethnicity, and 7 were of other ethnicities. Onethird had a tertiary education. Their ages ranged from 39 to 87 years, with an average age of 66 years.

Some 32 patients were from the

(Figure 1). They were then asked (1) whether information presented by each of these methods would encourage them to take the medication daily, (2) which method they preferred for expressing the medication's benefit, and (3) whether they preferred positively or negatively framed information. Patients were also asked whether they preferred that physicians give them numbers and risks or give them their own opinion.

We entered the raw data into Microsoft Excel practice in the low-income area, 33 were from the practice in the middle-income area, and 15 and 20 were from the 2 practices in high-income areas. Fortyseven percent of patients demonstrated basic numeracy skills. Patient ethnicity, education, and numeracy differed significantly across practices; ${ }_{i}$ however, when these 3 factors were entered into logistic regression models that estimated perceived risk of heart attack or preferred format for communicating benefit, adding 
practice to the model did not significantly alter the results. We therefore analyzed patients from all practices together. Eighty-one percent of patients were willing to take medication daily for the rest of their lives to protect their hearts.

Table 1 shows that no matter which method was used to express the benefit of the new medication, the great majority of patients (67\%-89\%) indicated that they would be encouraged to take it.

Sixty-eight participants could decide which of the 8 methods they considered to be the best for expressing benefit (the others could not make this decision). Of these $68,39(57 \%)$ preferred the graph, which was significantly more $(P<.001)$ than the $13(19 \%)$ who chose the next most preferred option, relative risk. Only 9 (13\%) preferred absolute risk (either positively or negatively framed), and 6 (9\%) preferred natural frequencies (either simplified or detailed). Only 1 patient preferred the odds ratio $(1 \%)$, and none preferred NNT.

Of those 69 patients who responded to the question on framing risk, 62 (90\%) preferred positive framing, consistent with other research. ${ }^{12,13}$

When asked whether they preferred physicians to give them numbers and risks or to give their opinion regarding treatment, about two-thirds of patients preferred the physician's opinion, compared with about one-fifth who preferred being presented with numbers and risks. The remaining roughly one-fifth of patients had no preference or were undecided. Sex, ethnicity, age, tertiary education, and willingness to take protective heart medication continuously for the next 5 years had no significant effect on whether patients preferred numbers and risks or a physician's opinion.

\section{DISCUSSION}

\section{Summary of Main Findings}

Most of the patients in our study, who had a history of prior heart attacks, angina, or both, would be encouraged to take a hypothetical medication to reduce their risk of a heart attack regardless of the way the medication's benefit was expressed. The graphical format, however, was by far patients' preferred method for learning about this benefit, followed by relative risk. NNT was the least preferred method.

To simplify the issue, we asked patients to consider potential benefits but not possible concurrent harms of the medication. Of course, the real-life situation is more complex, requiring the balancing of both potential benefits and harms.

\section{Strengths and Limitations}

A strength of this study is that it was conducted among patients with known heart disease, a population who have been asked to make related decisions in real life, who therefore had an informed point of view when asked to make the hypothetical decisions required for this study. A similar previous study ${ }^{4}$ used a younger group of patients who were healthy. The age of patients and their actual health status may change the dynamics of decision making.

All the patients in our study were taking statins, which is both a potential strength and weakness. Anecdotally, we know of very few patients with ischemic heart disease who actively chose not to start taking lipid-lowering medication, although only about onehalf remain on statins long term, so our study patients may not be typical. They would, however, be well aware of any inconveniences associated with taking drugs for extended periods as proposed in the scenario presented to them. The study was not done at the point of true decision making, which would have required a different design and setting, most appropriately in secondary care at the point of discharge. This approach would have been considerably more complex and expensive, however. Moreover, such a study would have its own biases. The strength of all participants taking statins was that it meant all were taking a drug that had similar benefits to the hypothetical medication we were proposing for them. This use also indirectly introduced an element of standardization.

We have presumed here that patient preference for a given format of explanation reflects their ease of understanding the information presented. A separate study would be required to confirm that patients correctly understood that information.

\section{Comparison With Existing Literature}

An earlier study of 100 primary care and cardiology outpatients similarly found that patients were least willing to consider taking a medication when the information about benefit was expressed as NNT compared with absolute or relative risk reduction. ${ }^{4}$ A graphical mode of expressing benefit was not an option in that study.

Although we found no correlation of patients' preferences with numeracy ability, such correlation may have been demonstrated with a larger sample size. Education plays an important role in whether patients are comfortable with numbers and thus can influence how they perceive risk, which is often expressed in numbers. ${ }^{14}$

\section{Implications}

The use of visual aids, as previously advocated by Paling ${ }^{15}$ and others, may be the best way to present the risks and benefits of treatment to patients. Although NNT provides useful information for clini- 
cians to enable them to compare the benefits and risks of interventions for a specific patient, this format was the least likely to encourage patients to take medication in our study.

In this study, we sought to differentiate between the persuasiveness of the method in which data are presented and the method that patients found best in helping them understand their risks and benefits. The decision to treat cardiovascular disease risk factors with drugs is in effect a "lifetime sentence" with both potential benefits and harms. It would be unethical for this decision to be made without informed consent. Certain formats of providing information may be more persuasive than others, but may not necessarily be the best way to help patients fully understand risks and benefits.

The greatest challenge is how to support decision making by providing information that is meaningful. It is therefore imperative that information on risk is communicated in ways that are understandable and acceptable to patients and also considered accurate by primary care practitioners. This study contributes to our knowledge on how to achieve this objective.

To read or post commentaries in response to this article, see it online at http://www.annfammed.org/cgi/content/full/6/3/213.

Key words: Cardiovascular disease; risk assessment; decision making; risk; patient education; dyslipidemia; drug therapy

Submitted June 20, 2007; submitted, revised, September 21, 2007; accepted October 9, 2007.

Acknowledgments: This study was funded by the National Heart Foundation of New Zealand. Thanks go to the family physicians who assisted in the study and especially to the participating patients.

\section{References}

1. Alaszewski A. A person-centred approach to communicating risk. PLoS Med. 2005;2(2):e41.

2. Edwards A, Elwyn G, Stott N. Communicating risk reductions. Researchers should present results with both relative and absolute risks. BMJ. 1999;318(7183):603; author reply 603-604.

3. Edwards A, Elwyn G, Covey J, Matthews E, Pill R. Presenting risk information-a review of the effects of "framing" and other manipulations on patient outcomes. J Health Commun. 2001;6(1):61-82.

4. Hux JE, Naylor CD. Communicating the benefits of chronic preventive therapy: does the format of efficacy data determine patients' acceptance of treatment? Med Decis Making. 1995;15(2):152-157.

5. Frich JC, Ose L, Malterud K, Fugelli P. Perceived vulnerability to heart disease in patients with familial hypercholesterolemia: a qualitative interview study. Ann Fam Med. 2006;4(3):198-204.

6. Goldman RE, Parker DR, Eaton CB, et al. Patients' perceptions of cholesterol, cardiovascular disease risk, and risk communication strategies. Ann Fam Med. 2006;4(3):205-212.

7. Bobbio M, Demichelis B, Giustetto G. Completeness of reporting trial results: effect on physicians' willingness to prescribe. Lancet. 1994;343(8907):1209-1211

8. Epstein RM, Alper BS, Quill TE. Communicating evidence for participatory decision making. JAMA. 2004;291(19):2359-2366.

9. Alaszewski A, Horlick-Jones T. How can doctors communicate information about risk more effectively? BMJ. 2003:327(7417):728-731.

10. Edwards A, Unigwe S, Elwyn G, Hood K. Effects of communicating individual risks in screening programmes: Cochrane systematic review. BMJ. 2003;327(7417):703-709.

11. Randomised trial of cholesterol lowering in 4444 patients with coronary heart disease: the Scandinavian Simvastatin Survival Study (4S). Lancet. 1994;344(8934):1383-1389.

12. Gigerenzer $G$, Edwards A. Simple tools for understanding risks: from innumeracy to insight. BMJ. 2003;327(7417):741-744.

13. Gurm HS, Litaker DG. Framing procedural risks to patients: is $99 \%$ safe the same as a risk of 1 in 100? Acad Med. 2000;75(8):840-842.

14. Schwartz LM, Woloshin S, Black WC, Welch HG. The role of numeracy in understanding the benefit of screening mammography. Ann Intern Med. 1997;127(11):966-972.

15. Paling J. Strategies to help patients understand risks. BMJ. 2003; 327(7417):745-748. 